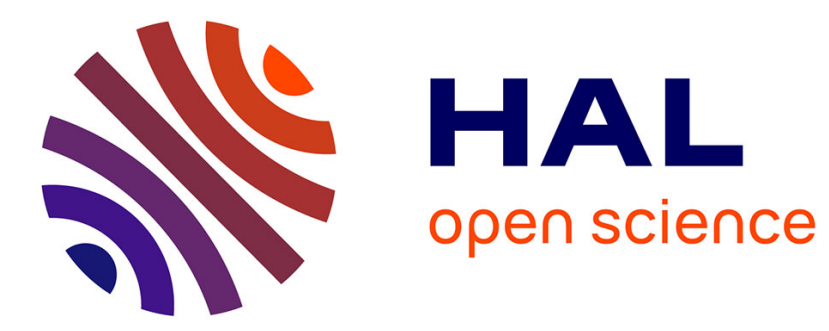

\title{
Relationship between mechanical properties and microstructure of yttria stabilized zirconia ceramics densified by spark plasma sintering
}

Arnaud Fregeac, Florence Ansart, Serge Selezneff, Claude Estournès

\section{To cite this version:}

Arnaud Fregeac, Florence Ansart, Serge Selezneff, Claude Estournès. Relationship between mechanical properties and microstructure of yttria stabilized zirconia ceramics densified by spark plasma sintering. Ceramics International, 2019, 45 (17 Part B), pp.23740-23749. 10.1016/j.ceramint.2019.08.090 hal02317401

\author{
HAL Id: hal-02317401 \\ https://hal.science/hal-02317401
}

Submitted on 16 Oct 2019

HAL is a multi-disciplinary open access archive for the deposit and dissemination of scientific research documents, whether they are published or not. The documents may come from teaching and research institutions in France or abroad, or from public or private research centers.
L'archive ouverte pluridisciplinaire $\mathbf{H A L}$, est destinée au dépôt et à la diffusion de documents scientifiques de niveau recherche, publiés ou non, émanant des établissements d'enseignement et de recherche français ou étrangers, des laboratoires publics ou privés. 


\section{OATAO \\ Open Archive Toulouse Archive Ouverte}

\section{Open Archive Toulouse Archive Ouverte (OATAO)}

OATAO is an open access repository that collects the work of Toulouse researchers and makes it freely available over the web where possible

This is an author's version published in: http://oatao.univ-toulouse.fr/24381

Official URL: https://doi.org/10.1016/j.ceramint.2019.08.090

\section{To cite this version:}

Fregeac, Arnaud

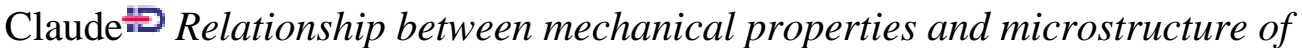
yttria stabilized zirconia ceramics densified by spark plasma sintering. (2019) Ceramics International, 45 (17 Part B). 23740-23749. ISSN 0272-8842

Any correspondence concerning this service should be sent to the repository administrator: tech-oatao@listes-diff.inp-toulouse.fr 


\title{
Relationship between mechanical properties and microstructure of yttria stabilized zirconia ceramics densified by spark plasma sintering
}

\author{
Arnaud Fregeac $^{\mathrm{a}, \mathrm{b}}$, Florence Ansart ${ }^{\mathrm{a}}$, Serge Selezneff ${ }^{\mathrm{b}}$, Claude Estournès ${ }^{\mathrm{a}, *}$

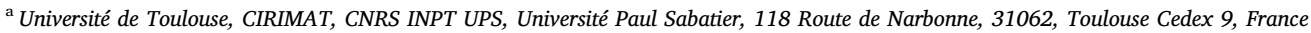 \\ ${ }^{\mathrm{b}}$ SAFRAN Aircraft Engines, 2 Rue Henri Auguste Desbruères, 91100, Corbeil-Essonnes, France
}

A R T I C L E I N F O

Keywords:

YSZ

Spark plasma sintering

Fracture surface

Mechanical properties

\begin{abstract}
A B S T R A C T
Porous ceramics are widely used for many applications such as filters, insulators, electrodes for SOFC, membranes or bone scaffolds, with porosity in the typically range of $20-50 \%$ vol. The functionality of those materials comes at the expense of the degradation of their mechanical properties which are highly impacted by the rate, distribution, shape and size of the porosity. Among them tetragonal stabilized zirconia (TSZ) is one of the most industrially used; it is sometime called: "the ceramic steel" since in its dense state it exhibits the highest toughness for ceramics. It is known that the porosity has a huge impact on the thermo-mechanical properties of refractory ceramics as Yittria Stabilized Zirconia (YSZ). This study aims to capitalize the mechanical properties as a function of porosity to provide future applications and ensure the behavior in service of thermal barrier coating.

In the present paper, the correlation between the microstructure and the mechanical properties such as Young modulus, hardness and strength of YSZ ceramics obtained by Spark Plasma Sintering (SPS) was investigated. Two types of YSZ powder, a nanometric one from Tosoh and a micrometric one obtained by sol-gel route were studied to prepare homogeneous mesoporous or oriented macroporous microstructure by partial sintering. SPS parameters have been determined and optimized to manage the porosity rate. Furthermore, a bimodal microstructure can be obtained, by mixing both powders, allowing the formation of linking bridges between the microporous zone and the nanopowder during sintering. The macroporous ceramics have lower Young modulus, hardness and strength than mesoporous ones. These characteristics are discussed in the paper taking into account the differences between microstructure and contacts between particles with various form factors. Thus, it is clearly evidenced that the morphology of raw powders and the level of porosity are key parameters to optimize the mechanical properties of such porous material.
\end{abstract}

\section{Introduction}

Yttria stabilized zirconia ceramics are well known in the field of thermal barrier coatings (TBC) due to their high ability to thermally insulate hot metallic parts of turbo-engines [1-3]. Traditional Atmospheric Plasma Sprayed (APS) TBC have a thermal conductivity of about $0.81 .2 \mathrm{~W} / \mathrm{mK}$ [4]. In the literature it is also proposed to shaped more porous TBC in order to reduce the thermal conductivity and reach low value as $0.4 \mathrm{~W} / \mathrm{mK}$ for porosity higher than $30 \%$ vol [5]. Another important step for such ceramics is to evaluate their mechanical properties in order to bring their multifunctional properties on metallic substrates exposed to severe environment [6]. Many processes such as template method, slip casting, gel casting, direct foaming or partial sintering of powder [7-10] have already been used to produce porous ceramics. In this paper, we choose to elaborate porous YSZ ceramics using a non-conventional shaping process: the Spark Plasma Sintering and to evaluate their mechanical properties.

This process, which belongs to the electric current assisted sintering technologies, allows to rapidly produce ceramic materials with high performances since nanosized grains are preserved in the microstructure [11-16]. Dudina et al. in their last review on porous materials fabricated by SPS underline that there is no article related to the consolidation of porous YSZ and their mechanical properties [17]. YSZ ceramics made by SPS are hugely studied for their high strength due to the fact that nanosized particles are kept despite the high density reached thanks to the high sintering kinetics of the process [18-22]. Furthermore, Monceau et al. [23] demonstrated the interest to apply in only one step from both ceramic and metallic powders, a porous YSZ

\footnotetext{
* Corresponding author.

E-mail address: estournes@chimie.ups-tlse.fr (C. Estournès).
} 
coating with a complete architecture as TBC on a superalloy substrate. They evaluated the working properties, in particular the oxidation resistance, upon thermic cycling and proved the robustness of TBCs obtained by the SPS process even after 1000 cycles at $1100^{\circ} \mathrm{C}$ without high spallation observed on them [24-26].

Mechanical properties of dense 3-YSZ are highly reported and discussed in literature since, as mentioned above, such material is used in many applications [27]. Mechanical properties of porous ceramics such as $\mathrm{Al}_{2} \mathrm{O}_{3}$ or YSZ made by conventional partial sintering are well known in the literature $[8,28-31]$ while, to the best of our knowledge, no one reported on the mechanical properties of porous YSZ consolidated by Spark Plasma Sintering. Compare to conventional sintering, SPS allows to densify materials at lower temperature and dwell time which lead to a better control of their microstructure [12,14]. Thus, using SPS, one can expect an increase of the mechanical properties. Further, there is no reports in literature on the mechanical properties of dense and/or porous 5.1 and 6 -YSZ materials.

As SPS allowed to explore a large range of microstructure and porosity, the aim in this study was to characterize the mechanical properties of the top coat (YSZ). We characterized those properties as a function of porosity which is known to impact the thermo-mechanical properties of the TBC. The knowledge of mechanical properties of free standing pellets is crucial for their use in full TBC systems, and/or thereof to predict their behavior by a numerical approach to optimize their architecture for example. In the present paper, we also compared those results with a conventional atmospheric plasma sprayed (APS) TBC.

\section{Materials and experimental procedures}

\subsection{Powders}

A commercial YSZ nanometric powder (Tosoh TZ-6Y, Tosoh Corporation, Tokyo, Japan $-99.2 \%$ purity - crystallite size of $60 \mathrm{~nm}$ and specific a rea of $14 \mathrm{~m}^{2} / \mathrm{g}$ ) and a 5.1 YSZ synthesized micronic powder (aggregate morphology, crystallite size of $65 \mathrm{~nm}$ and specific area of $0.7 \mathrm{~m}^{2} / \mathrm{g}$ ) were used as raw materials in this study. Both powders will be named in the rest of the article T6YSZ and YSZ(SG) respectively. The synthesized powder was prepared by sol-gel route using as precursors zirconium propoxide (Merck, $70 \mathrm{wt} \%$ in 1-propanol) and yttrium nitrate (Merck, purity 99,8\%) in 1-propanol (Merck, purity 99,7\%) and then dried at $50{ }^{\circ} \mathrm{C}$ in an oven before calcination during $2 \mathrm{~h}$ at $1000{ }^{\circ} \mathrm{C}$ as described in previous works made in our laboratory [32,33]. The yttrium amount either in the commercial powder or in the synthesized one was chosen in order to get a non-transformable phase (metastable tetragonal phase t').

The raw powders were consolidated without any further treatment while for the composites (75\%vol YSZ(SG) - 25\%vol T6YSZ and 50\%vol YSZ(SG) - 50\%vol T6YSZ), the powders were previously mixed in a dry way using a Turbula ${ }^{\circledR}$ device (T $2 \mathrm{~F}$ type) with an equivalent mass of ball of milling and powder during $2 \mathrm{~h}$ before densification.

\subsection{Consolidation of pellets}

The zirconia based powders were spark plasma sintered using a Dr. Sinter 2080 unit, SPS Syntex Inc., Japan, available at the Plateforme Nationale de Frittage Flash located at the Université Toulouse 3 Paul Sabatier, using $\emptyset 20 \mathrm{~mm}$ Graphite die lined with a $0.2 \mathrm{~mm}$ graphite paper (PERMA-FOIL ${ }^{\oplus}$ Toyo Tanso). A dc pulsed current with sequence of 12:2 (on-off) was a pplied to heat the tool and the sample. The temperature was monitored using a pyrometer focused on a hole, $1.8 \mathrm{~mm}$ in diameter and $3 \mathrm{~mm}$ deep, located at the external surface of the die. The pressure was applied at room temperature and the rate of temperature was set to $100^{\circ} \mathrm{C} / \mathrm{min}$ for heating and $25^{\circ} \mathrm{C} / \mathrm{min}$ for cooling stages. The SPS parameters were varied in order to access a large range of porosity, from 2.5 to $52 \%$ vol.
The appropriate amount of powder is poured into the die in order to obtain pellets of about $3 \mathrm{~mm}$ in thickness after sintering. After sintering, all specimens were annealed at $800{ }^{\circ} \mathrm{C}$ to remove the graphite foil and proceed to a reoxydation of the YSZ exposed during SPS to low oxygen partial pressure atmosphere leading possibly to the formation oxygen vacancies upon the sintering conditions (i.e.: temperature) [34,35]. Pellets were then polished before mechanical tests with SiC discs with grade from 120 to 4000 . We did not used diamond or colloidal solution for porosity higher than $10 \%$ because after testing the diamond paste solution remains into the porosity and induces important stripes, and the colloidal solution is incorporated into the microstructure even after washing in an ultrasonic bath. After preparation, the porosity was measured by water intrusion which allowed to access the amount of total, open and closed porosity [36].

\subsection{Young' modulus determination}

Young modulus (E) was determined by impulse excitation technique following the ASTM E1876 on disc sample. According to this test procedure the pellet is supported by two nylon strings as closed as possible of the nodal line and a brief impulse is given on the sample using a hammer. The acoustic signal is detected by a microphone with sensitivity from $20 \mathrm{~Hz}$ up to $50 \mathrm{kHz}$. The frequencies of the torsion and flexion modes and their ratio are measured and with the dimension of the sample it is possible to determine the Poisson's ratio and finally to determine the Young modulus.

\subsection{Hardness}

Hardness is measured via a micro Vickers Hardness Testing Machines (HM200) with an applied load of $2.98 \mathrm{~N}$ for $15 \mathrm{~s}$ on polished surfaces with SiC disc until 4000 (and down to $1 \mu \mathrm{m}$ for sample with less than $10 \%$ of porosity). The hardness was determined according to equation (1):

$H v=1.853 P / d^{2}$

where $\mathrm{P}$ stands for the applied load (in $\mathrm{N}$ ) and $\mathrm{d}$ stands for the diagonal length of the indentation in $\mathrm{mm}$.

Almost ten measurements are performed for each composition and the average hardness value is given.

\subsection{Flexural strength}

Flexural strength $(\sigma)$ was determined by three points bending at room temperature using a MTS $1 / \mathrm{M}(5 \mathrm{kN})$ testing machine on parallelepiped polished samples with dimensions of $2 \mathrm{~mm} \times 1.5 \mathrm{~mm} \times 20 \mathrm{~mm}$ and a span length of $13 \mathrm{~mm}$. To reduce the risk of sample failure initiating from an edge, they were chamfered at $45^{\circ}$ using a $1200 \mathrm{SiC}$ disc. The cross-head speed was set at $0.1 \mathrm{~mm} / \mathrm{min}$. Results presented correspond to the average values of 5 measurements.

Flexural strength was calculated according to the following equation (2):

$\sigma=\frac{3 d}{2 b h^{3}} L$

Where $d$ the length between the span, $b$ the width and $h$ the height of the sample and $\mathrm{L}$ the applied load.

\section{Results and discussion}

\subsection{Morphology}

The microstructures of the YSZ were observed by field-emission scanning electron microscopy (SEM-FEG FEI Quanta 250) and analyzed to evaluate the grain size using an image analysis software (Image J), about 30 measures are done. 

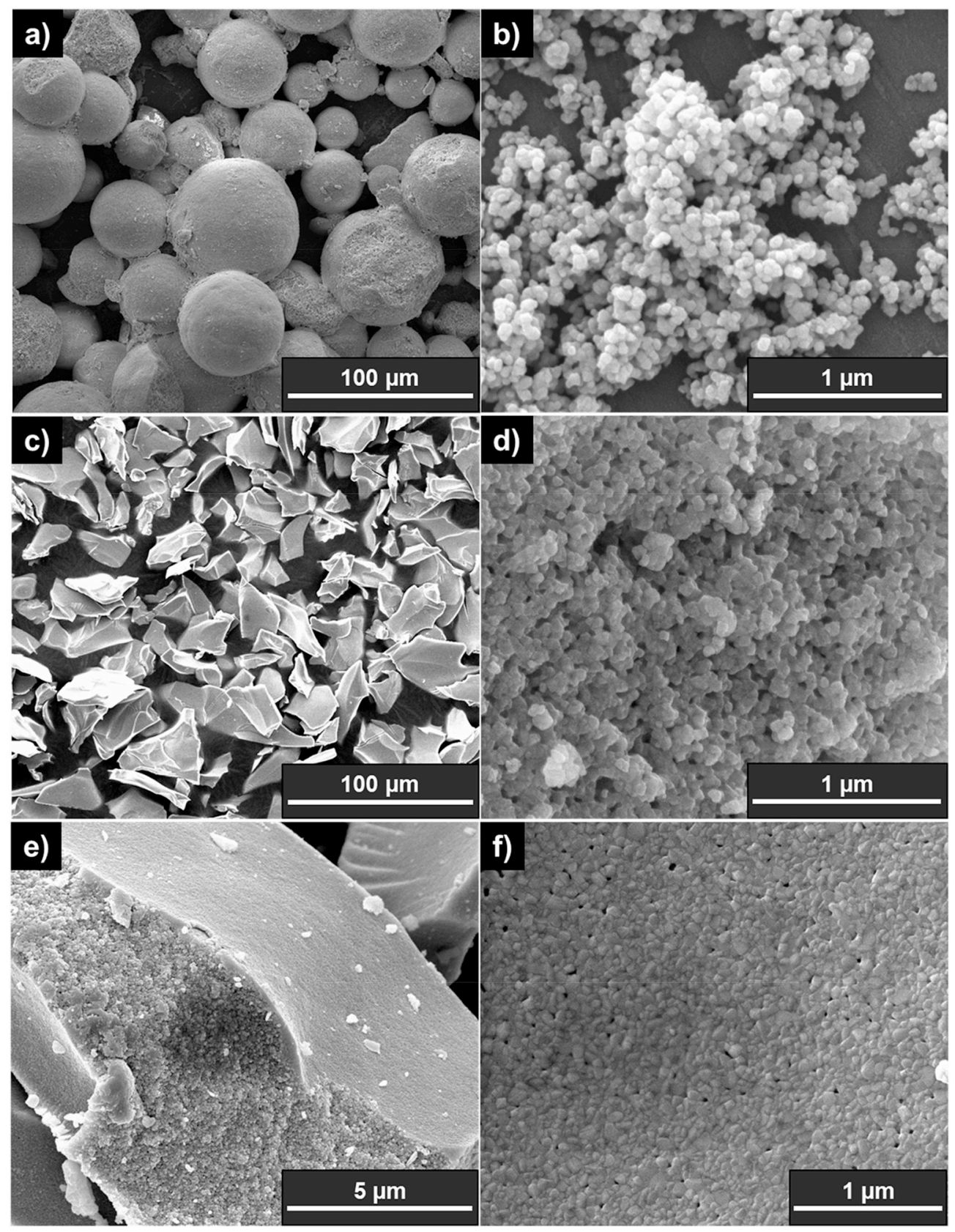

Fig. 1. SEM-FEG images of the YSZ powders. On the top (T6YSZ) a) Agglomerates b) Grains after grinding. On the bottom (YSZ(SG)) c) aggregates after calcination at $1000^{\circ} \mathrm{C} \mathrm{d}$ ) Grains e) fracture of an agglomerate f) Surface of agglomerates.

The commercial powder consists of porous agglomerates (62 $\pm 7 \mu \mathrm{m}$ ) of nanoparticles (Fig. $1 \mathrm{a}$ and b) and the synthetized one is composed of aggregates of $40 \mu \mathrm{m}$ in length and $10 \mu \mathrm{m}$ in width (Fig. $1 \mathrm{c}$ and d) with important cohesion between crystallites inside and closed porosity. A dense layer is present on the surface of the aggregates with a thickness in the range $200-400 \mathrm{~nm}$ as seen on the broken aggregate in (Fig. 1 e and f). This layer might be a consequence of the heat treatment of the xerogel, at $1000{ }^{\circ} \mathrm{C}$ during $2 \mathrm{~h}$ in order to obtain the oxide powder, leading to the initiation of sintering on surface. The microstructures and particularly the presence of the dense layer at the surface YSZ(SG) aggregates can explain the difference in the specific area observed for the two materials.

\subsection{Structure}

Fig. 2 presents the powder X-ray diffraction patterns obtained for the T6YSZ and YSZ(SG). The major phase observed is the tetragonal one with some amount of the monoclinic for the T6YSZ while only the tetragonal is detected in the YSZ(SG) sample. After sintering the monoclinic phase initially present in the T6YSZ powder is transformed into tetragonal (inset Fig. 2).

In order to estimate the proportion of each phase by the intensity ratio method, we used the following equations (3)-(5) proposed by Garvie et al. [37] and Toraya et al. [38].

$V m=\frac{1,311 x}{1+0,311 x}$

$x=\frac{I_{m}(\overline{1} 11)+I_{m}(111)}{I_{m}(\overline{1} 11)+I_{m}(111)+I_{t}(101)}$

$V t=1-V m$

Where $\mathrm{Vm}$, Vt represents the amount (\%vol) of each phase respectively 


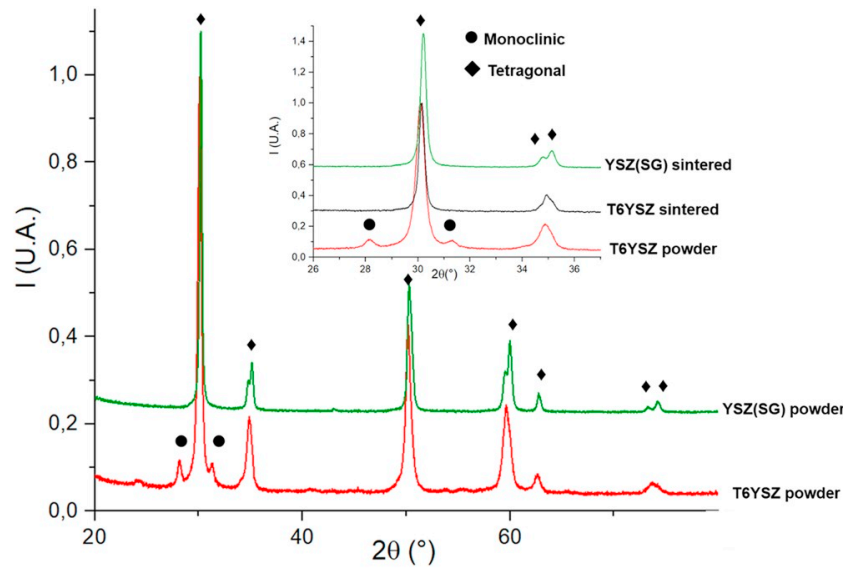

Fig. 2. XRD pattern of the T6YSZ et YSZ(SG) powder. A focus is done on the evolution of XRD pattern for the T6YSZ and YSZ(SG) before and after SPS sintering.

Table 1

Quantification of each phase of the powder and the sintered powder.

\begin{tabular}{lllll}
\hline & T6YSZ & & YSZ(SG) & \\
& Powder & Sintered & Powder & Sintered \\
CM & $11 \%$ & $0 \%$ & $0 \%$ & $0 \%$ \\
CT & $89 \%$ & $100 \%$ & $100 \%$ & $100 \%$ \\
\hline
\end{tabular}

monoclinic and tetragonal.

Table 1 presents the quantification of YSZ phase calculated from Eqs (3)-(5). The percentage of monoclinic phase decreased from 15 to $3 \%$ in the T6YSZ before and after sintering (it is the case for low temperature of $1000{ }^{\circ} \mathrm{C}$ but also for high temperature of sintering of $1150^{\circ} \mathrm{C}$ ) and it is transformed into tetragonal phase. No phase transformation is visible for the YSZ(SG) powder. But as expected before the main phase is the tetragonal one and both powders exhibit the same structure after sintering.

\subsection{Porosity}

The results of the porosity rates (total, open and closed) are reported in Table 2 as a function of SPS parameters. As expected, when the temperature, the pressure or the dwell time increases the porosity of all the samples decreases. The evolution of the porosity as a function of the temperature and dwell time is also presented on the graphs of Fig. 3. For temperature of 1000 and $1100{ }^{\circ} \mathrm{C}$ under $25 \mathrm{MPa}$ (Fig. 3a), the YSZ (SG) pellets exhibit a lower total porosity than the T6YSZ one. The crystallite size of the two powders is similar so it was expected that the T6YSZ powder could have a higher reactivity due to the higher specific surface but it is not the case. It could be explained by the fracture of the dense layer of the YSZ(SG) aggregate even under low pressure as $25 \mathrm{MPa}$ or in this case the agglomerates of T6YSZ are not all destroyed implying a lower density of the green body of the powder. To remember, the pressure is applied at room temperature before the heating rise. The mixture at ratio 50/50, has an intermediate porosity between those of YSZ(SG) and T6YSZ pellets. At $1150{ }^{\circ} \mathrm{C}$, the T6YSZ pellets have a lower porosity than the YSZ(SG) one.

Under $50 \mathrm{MPa}$ (Fig. 3b), the porosity of the YSZ(SG) pellets is lower than of the T6YSZ one for temperature less than $1100^{\circ} \mathrm{C}$. It seems that the YSZ(SG) has a lower decrease of the porosity when the temperature increases from 1100 to $1150^{\circ} \mathrm{C}$ than the T6YSZ. The ceramic shaped from the mixture is more porous in this case and this could be due to a "rigid inclusion" effect on the sintering of the composite. Yan et al. pointed out the retarding effect of the sintering when large particles are mixed with finer ones and this is more pronounced when the size ratio between particles increased [39]. Hirata et al. also reported this effect and they attributed the impact of the lowest sintering for composite in bimodal system to the fractional collision frequency, related to the type of contact of particles (large-large, small-large, small-small), which evolved with the size and the quantity of powder [40].

At $1150{ }^{\circ} \mathrm{C}$ under $50 \mathrm{MPa}$ (Fig. $3 \mathrm{c}$ ), when the dwell time increased, the porosity decreased slowly for $5 \mathrm{~min}$ and quickly for $10 \mathrm{~min}$ for the three compositions.

For low consolidation temperature, YSZ(SG) pellets are denser than T6YSZ ones, this is due to the low annealing treatment of the YSZ(SG) powder compare to T6YSZ which could increase its reactivity inducing more advanced sintering. For high temperature $\left(\geq 1150^{\circ} \mathrm{C}\right)$ in addition to the reactivity due to the size of the particles, the higher densification of the T6YSZ could be also attributed, as mentioned by Chaim, to the better grain arrangement. This can be attributed to the sphericity of T6YSZ nanoparticles or easier particles sliding by viscous effect which lead to an increase of the relative contact area between particles [41].

\subsection{Microstructure}

The microstructures of the different systems are presented in Fig. 4. T6YSZ pellets exhibit a homogeneous nanostructure with the presence of mesopores (Fig. $4 \mathrm{a}$ and b). The evolution of the microstructure as a function of the porosity is presented on Fig. 5 and Fig. 6. The nanostructure is homogeneous at a large scale for dense and porous microstructures and always exhibits mesoporosity. The BET analysis relative to the pore distribution for the T6YSZ sample with a total porosity of $23.6 \% \operatorname{vol}\left(1100{ }^{\circ} \mathrm{C}-50 \mathrm{MPa}-1^{\prime}\right)$ reveals a principal size of pore with an average diameter of $30 \mathrm{~nm}$.

The YSZ(SG) has an oriented macroporous microstructure (Fig. 4 c and d). Due to their morphology, the grains of the YSZ(SG) are more or less oriented perpendicular to the applied pressure, the direction of which represented by the red arrows. This leads to microstructure

Table 2

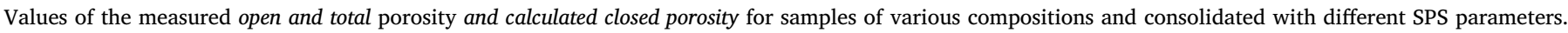

\begin{tabular}{|c|c|c|c|c|c|c|c|c|c|c|c|c|c|c|}
\hline \multirow{2}{*}{$\begin{array}{l}\text { Sintering } \\
\text { Temperature }\left({ }^{\circ} \mathrm{C}\right)\end{array}$} & \multirow{2}{*}{$\begin{array}{l}\text { Pressure } \\
(\mathrm{MPa})\end{array}$} & \multirow{2}{*}{$\begin{array}{l}\text { Sintering time } \\
(\mathrm{min})\end{array}$} & \multicolumn{3}{|l|}{ T6YSZ } & \multicolumn{3}{|l|}{ YSZ(SG) } & \multicolumn{3}{|c|}{0.5 T6YSZ/0.5 YSZ(SG) } & \multicolumn{3}{|c|}{0.75 T6YSZ/0.25 YSZ(SG) } \\
\hline & & & $\begin{array}{l}\text { Total } \\
\text { porosity (\%) }\end{array}$ & open & closed & $\begin{array}{l}\text { Total } \\
\text { porosity (\%) }\end{array}$ & open & closed & $\begin{array}{l}\text { Total } \\
\text { porosity }(\%)\end{array}$ & open & closed & $\begin{array}{l}\text { Total } \\
\text { porosity (\%) }\end{array}$ & open & closed \\
\hline 1000 & 25 & 1 & 52.0 & 51.8 & 0.2 & 40.1 & 30.0 & 10.1 & 45.3 & 37.8 & 7.4 & - & - & - \\
\hline 1050 & 25 & 1 & 43.5 & 42.9 & 0.6 & - & - & - & - & - & - & - & - & - \\
\hline 1050 & 50 & 1 & 35.6 & 34.3 & 1.3 & 32.8 & 22.9 & 9.9 & 38.2 & 31.3 & 6.9 & - & - & - \\
\hline 1075 & 50 & 1 & - & - & - & - & - & - & - & - & - & 34.7 & 25.4 & 9.3 \\
\hline 1100 & 25 & 1 & 38.0 & 37.1 & 0.9 & 34.6 & 23.5 & 11.2 & 34.9 & 27.8 & 7.0 & 26.1 & 13.6 & 12.4 \\
\hline 1100 & 50 & 1 & 23.6 & 22.5 & 1.1 & 23.7 & 13.9 & 9.8 & 26.6 & 19.1 & 7.5 & 25.6 & 17.5 & 8.1 \\
\hline 1150 & 25 & 1 & 23.0 & 22.0 & 1.0 & 26.6 & 16.2 & 10.8 & 32.4 & 26.6 & 5.8 & - & - & - \\
\hline 1150 & 50 & 1 & 10.9 & 8.6 & 2.3 & 18.5 & 7.8 & 10.8 & 26.1 & 19.7 & 6.3 & - & - & - \\
\hline 1150 & 50 & 5 & 10.3 & 7.4 & 2.9 & 15.8 & 5.2 & 10.5 & 24.9 & 17.9 & 7.0 & 24.4 & 15.9 & 8.5 \\
\hline 1150 & 50 & 10 & 2.5 & 1.5 & 1.0 & 10.5 & 1.9 & 8.6 & 13.2 & 3.5 & 9.7 & - & - & - \\
\hline
\end{tabular}




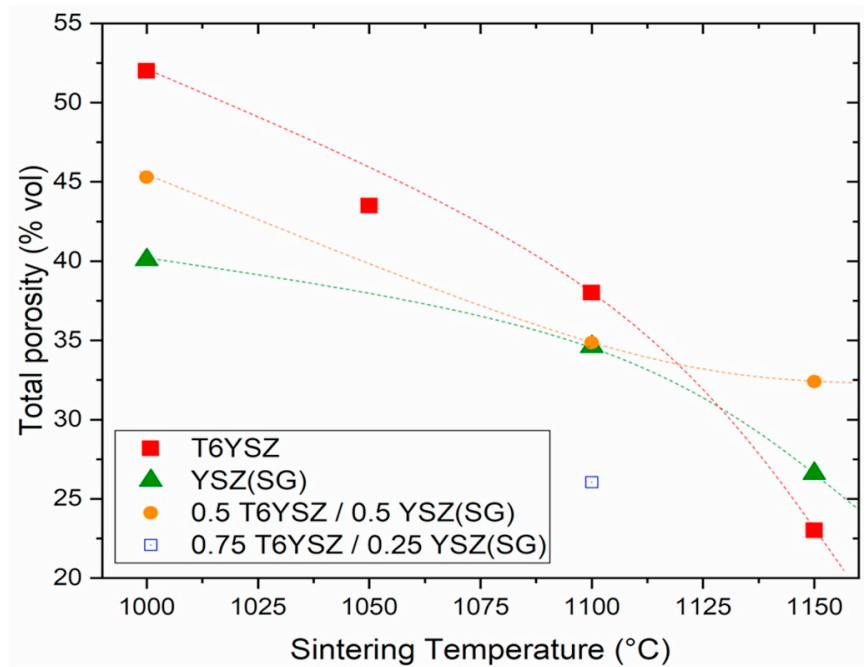

a)

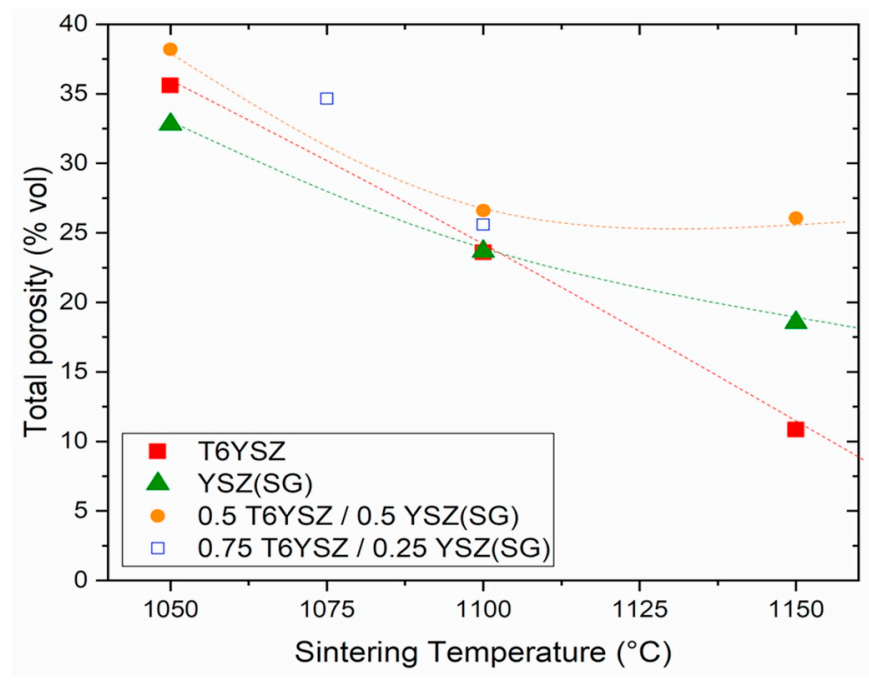

b)

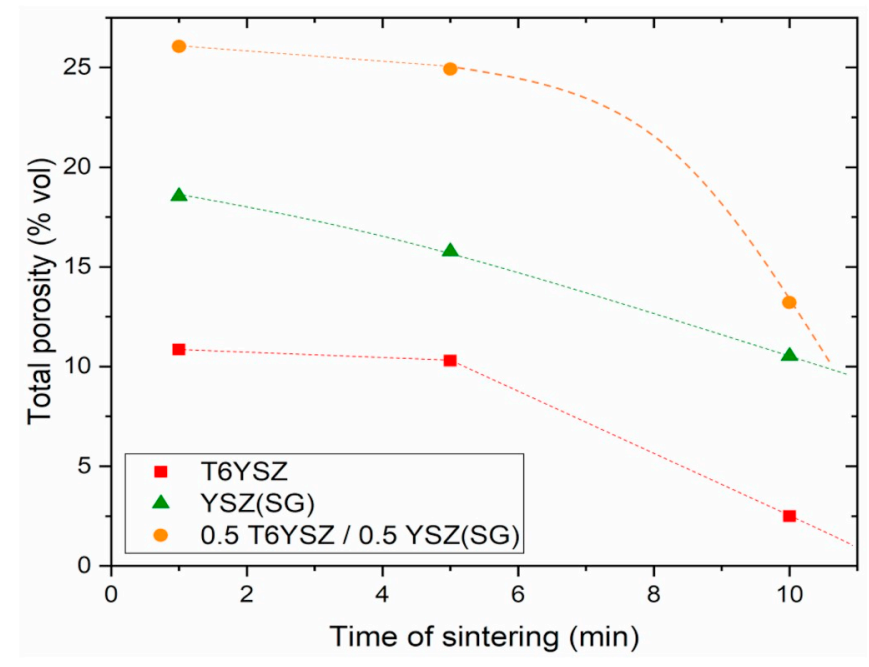

c)

Fig. 3. Evolution of the total porosity as a function of the sintering temperature and composition for a sintering pressure of a) $25 \mathrm{MPa}$ and $1^{\prime}$ of dwell time b) 50 MPa and $1^{\prime}$ of dwell time c) $50 \mathrm{MPa}$ and $1150^{\circ} \mathrm{C}$ as a function of dwell time. relatively similar to those obtained with APS [42]. Indeed, APS microstructure is also oriented because of the impingement and spreading of molten droplets onto a substrate. The size of the splat in APS microstructure depend on the spray parameters but the drops are often larger than $100 \mu \mathrm{m}$ by $1.5-3 \mu \mathrm{m}$ of thickness $[43,44]$, which is different from the YSZ(SG). As shown in Figs. 5 and 6 the dense YSZ(SG) microstructure presents some close porosity between sintered aggregates. When the porosity increased, the macroporous and open porosity are more important. When the targeted temperature and pressure are raised, the densification occurred between the agglomerate of the YSZ (SG) powder, the cohesion depends of the contact between particles which is managed by the shape of the particles while in thermal spray coating it is managed by the contact ratio between splat [44]. Moreover, the microstructure is more homogeneous in YSZ(SG) sample than APS because of the absence of semi-molten area [45]. Nevertheless, the pore size measured by image analysis (with Image $\mathrm{J}$ software) is almost distributed with an average width of $20 \mu \mathrm{m}$ and a thickness of $7 \mu \mathrm{m}$ for the YSZ(SG) powder sintered under the same conditions as previous described and a porosity of $23.7 \%$.

Same orientation is also visible on the 50/50 composites where the T6YSZ particles fill the porosity (Fig. 4 e). At high magnification the necks between the grains of the two materials are visible, the T6YSZ grains are linking the YSZ(SG) aggregates (Fig. $4 \mathrm{f}$ ). The mixture possesses both mesoporous and macroporous networks. In this case, it can be underlined that the closed porosity of the mixture is lower than the YSZ(SG) only. The behavior seems to follow a mixture law. The mixture demonstrates very cohesive microstructure even for high level of porosity such as $44 \%$.

It is shown (Figs. 5 and 6) that sintered ceramics exhibit different fracture surfaces. Indeed, while for the nanopowders (T6YSZ), the fracture surface mainly corresponds to inter-crystallites fractures, two fracture modes (intra and inter-aggregates) can be observed for the micrometric powder (YSZ(SG)), that we also find in the mixture. An hypothesis to explain this difference of fracture surface can be that the compaction and cohesion of the nanopowder are better than the micropowder ones, due to higher exchange surfaces between the grains [46], leading to a more cohesive structure and better mechanical properties. Then the weak interface between the agglomerates of the micropowders leads to easier transgranular fracture.

The next step was the investigation of the evolution of the size of grains when the temperature increased under $50 \mathrm{MPa}$ for $1 \mathrm{~min}$ (Table 3). The YSZ(SG) composition has a lower grain growth with the temperature increase compared to the nanometric one. Whereas the grain growth of the nanoparticles and microparticles in the mixture is slowed down that should be in relationship with the "rigid inclusion" effect of the aggregates particles.

\subsection{Mechanical properties}

\subsubsection{Hardness}

Fig. 7 presents the evolution of the Vickers microhardness as a function of the total porosity for the different compositions. First of all, one can note that when the porosity rate increases the hardness decreases. For a given rate of porosity, T6YSZ pellets have higher hardness than YSZ(SG) and the composites. This can be attributed to the low size of pores and the higher contact surface between particles.

YSZ(SG) with porosity of $10 \%$ has only closed pores, this can explain the hardness increase because there is no open pore at the surface and so the volume deformed by the indentation with $2.9 \mathrm{~N}$ load might be not enough to take into account a representative volume with closed porosity.

For comparison, the evolution of the Vickers microhardness of conventionally sintered 3YSZ nanoparticles [31] (Luo et al.) and SPS of 8YSZ particles [18,19] (Tosoh by Munir et al.) are represented on Fig. 7. The SPS pellets exhibit higher hardness than conventional ones. Munir et al. obtained equivalent hardness for equivalent sintering temperature 


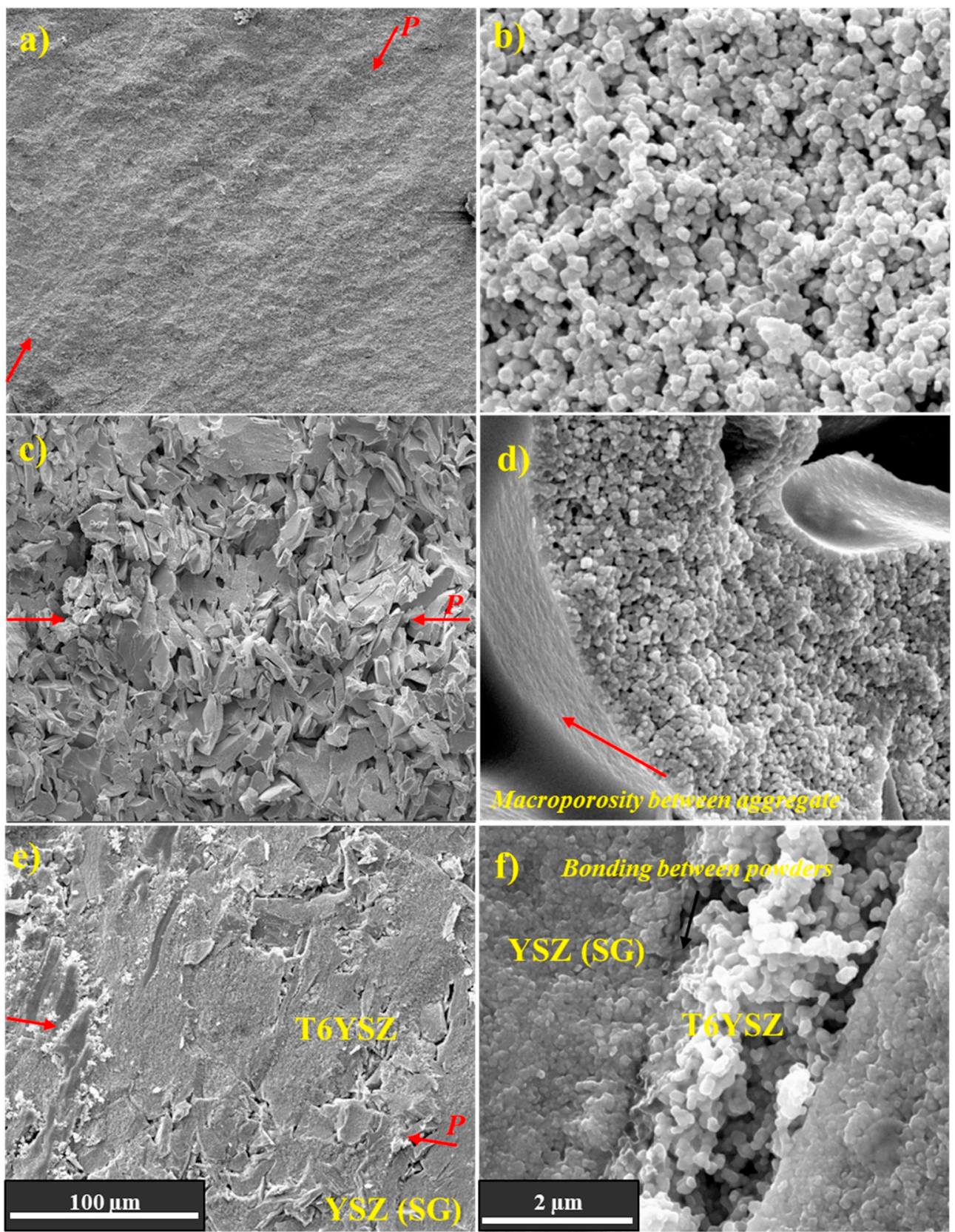

Fig. 4. SEM-FEG Microstructure of the different composition after sintering at $1100^{\circ} \mathrm{C}-50 \mathrm{MPa}-1$ '. T6YSZ: a) and b) respectively low and high magnification; YSZ (SG) c) and d) respectively low and high magnification; Composite 50/50 respectively low and high magnification.

but in the case of higher sintering pressure of $106 \mathrm{MPa}$ and a dwell time of 5' (in comparison we used 25-50 MPa and only $1 \mathrm{~min}$ of dwell time). The highest values for the full dense samples increased with the increase of grain sizes (with sintering temperatures of 1200-1300 $-1400{ }^{\circ} \mathrm{C}$ and an increased from 100 to $700 \mathrm{~nm}$ ). This verdict is also verified for 1 and 1.5 YSZ samples uniaxialy pressed and conventionally sintered with a grain size from 60 to $110 \mathrm{~nm}$ which present an increase of the Vickers hardness from 8 to approximatively 10,5 GPa [47]. For against, conversely, Trunec [48] shown that the hardness decreased with increasing the grain size for 3YSZ nanocrystalline powder. The powder was cold isostatically pressed at $1000 \mathrm{MPa}$ and sinter under air. The hardness decreased from $12.6 \mathrm{GPa}$ with a grain size of $190 \mathrm{~nm}$ to $10.9 \mathrm{GPa}$ for a grain size of $1790 \mathrm{~nm}$.

\subsubsection{Young modulus}

Fig. 8 presents the evolution of the Young modulus measured by acoustic emission bending as a function of porosity rate. The value of the dense bulk YSZ(SG) is near of $200 \mathrm{GPa}$ as expected. Until $20 \%$ of porosity, the T6YSZ and YSZ(SG) structure exhibits the same decrease of the Young modulus as a function of porosity, and no effect of the pore shape is observed as it was claimed by different authors [31,49]. Whereas the nanostructure as a pseudo-linear decreased in the range of $0-50 \%$ vol of porosity which matches well with the Boccaccini model for spherical particles taking account of the particle size ratio (length/ width) [50]. The decreased is more pronounced for the YSZ(SG) samples for porosity higher than $20 \%$ which can be related to the lower strengthening and cohesion of the aggregates for high rate of porosity. The mixture exhibits lower Young modulus than the sintered powders only for porosity lower than 30\%vol and have higher modulus than YSZ (SG) samples for high level of porosity. The lower modulus is attributed to a non-contact between aggregates of YSZ(SG) in the microstructure of the mixture and so, only links are made by the T6YSZ powder. The 

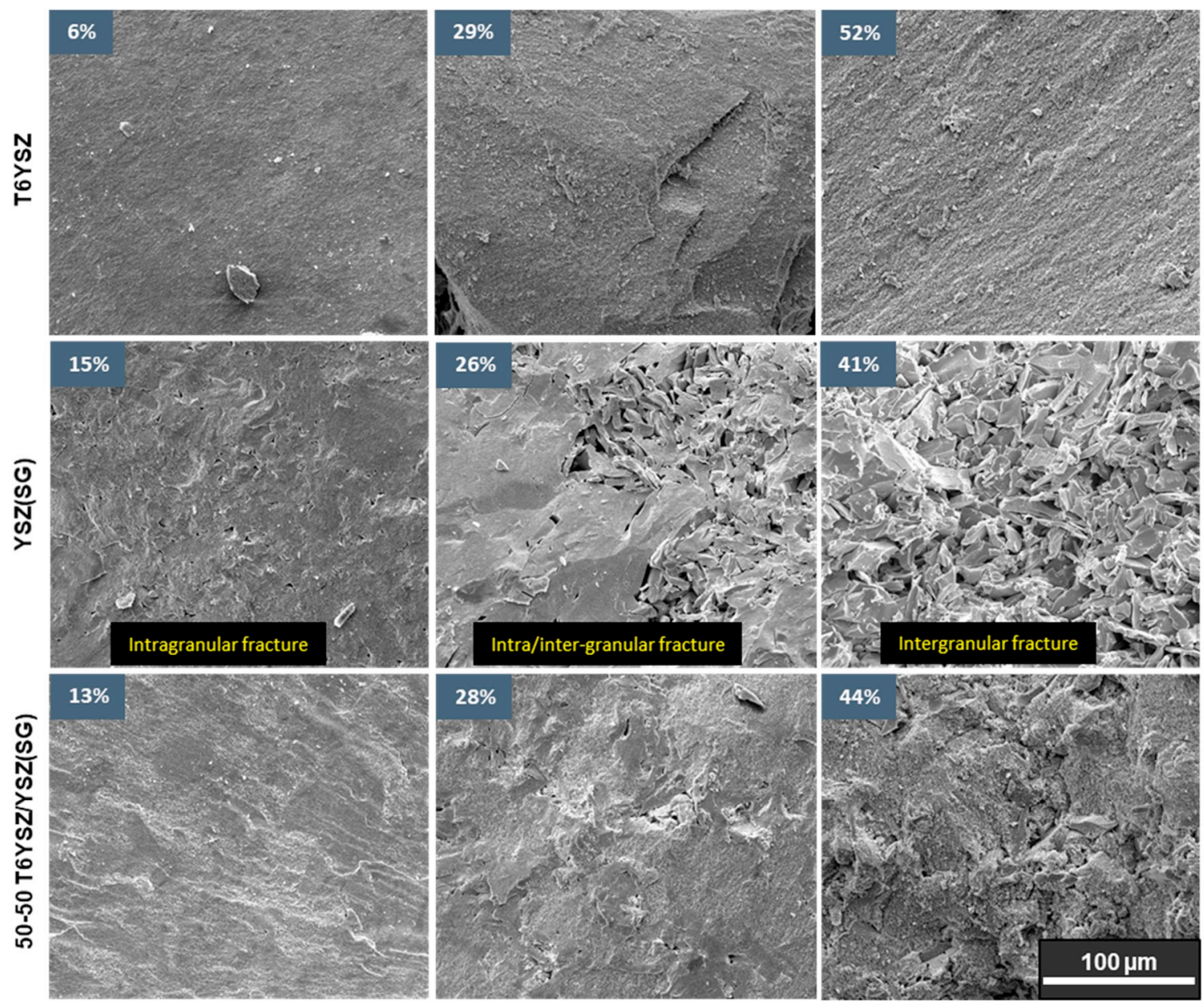

Fig. 5. SEM-FEG microstructure of the different powders for low, medium and high level of porosity at a low magnification.

reinforcement expected is obtained for high level of porosity where the behavior is directed by the T6YSZ.

Finally, for comparison, we also did impulse excitation measurements on a plasma spray thermal barrier coating (reference system) with $10-15 \%$ porosity that exhibit only a Young modulus perpendicular to the coating plane of $20 \mathrm{GPa}$. These results are in good agreement with the literature [51]. Concerning the microstructure it is explained by the low bonding ratio and also by the contact area between splats [52]. Li et al. [44] proposed a model to be applied to calculate the bonded ratio, and so estimate the Young modulus. In our case, the APS samples have an estimate bonding ratio of $26 \%$ from the literature data of Li et al. [44]. This low consolidation state significantly impacts the mechanical properties during thermal aging at high temperature and so causes the degradation of the TBC by the stiffening of the microstructure induced by the sintering of the splats [53]. So as it was demonstrated before, it is possible to apply YSZ TBC coating with the nanostructure of this work by SPS and we know now that the mechanical properties are higher than APS samples for similar thermal conductivity [54]. It was proved that the TBC made by SPS reached the same performances in terms of aging than classical TBC [55].

\subsubsection{Flexural strength}

The strength is related of the microstructure, pore size, shape and distribution, and so correlated to contacts between particles [56]. Fig. 9 shows the evolution of the flexural strength as a function of the total porosity rate.

For porosity rate lower than $20 \%$, the YSZ(SG) exhibits higher flexural strength than the others samples. This is correlated with nonconnected porosity (only closed porosity for porosity $<10 \% \mathrm{vol}$ ) and so a more important solid continuum phase than for the T6YSZ which only has open porosity.

For porosity rate higher than $20 \%$, the T6YSZ microstructure exhibits a higher strength compare to the others sample. This is related to the spherical pores against stripe and ring-like pores in the YSZ(SG) and the composites, but also to the lowest contact between particles due to the acicular and elongated shape of the YSZ(SG) powder [57]. Indeed in their study, Roberts et al. [58] calculated by Finite Element Modeling (FEM) the strength on porous model ceramics with different shapes and porosity rates. They underlined for a porosity rate of $20 \% \mathrm{vol}$ that ellipsoidal pores tend to weaken a structure more than a spherical pore. This is due to a combination of less well-connected solid phases in the case of ellipsoidal pore with a macroscopically connection of pores. Shimonosono et al. pointed out that the coordination number (i.e.: the number of contact between a grain and its closed neighbors) between particles increased with the strength. It is known that spherical and small particles as the nanoparcticles of the T6YSZ induce higher coordination number than elongated particles and so more necks are formed between particles which improve the strength [59].

The composites (50-50 and 75-25) have an intermediary strength (the strength of the 50-50 is higher than the strength of the 75-25) between the two pure systems and the behavior seems to be correlated once again with the intermediate closed porosity.

We compared these results with the work of Boccacini et al. [60] where $3 \%$ mol YSZ samples were prepared by tape casting with pore former leading to pore size in the range of $0.32-0.82 \mu \mathrm{m}$. They measured the strengths by ball-on-ring technique and the data are plotted on Fig. 9. We reached the same result as them for low porosity level but the strength of the gel-casting samples is higher for porosity $>40 \% \mathrm{vol}$. 

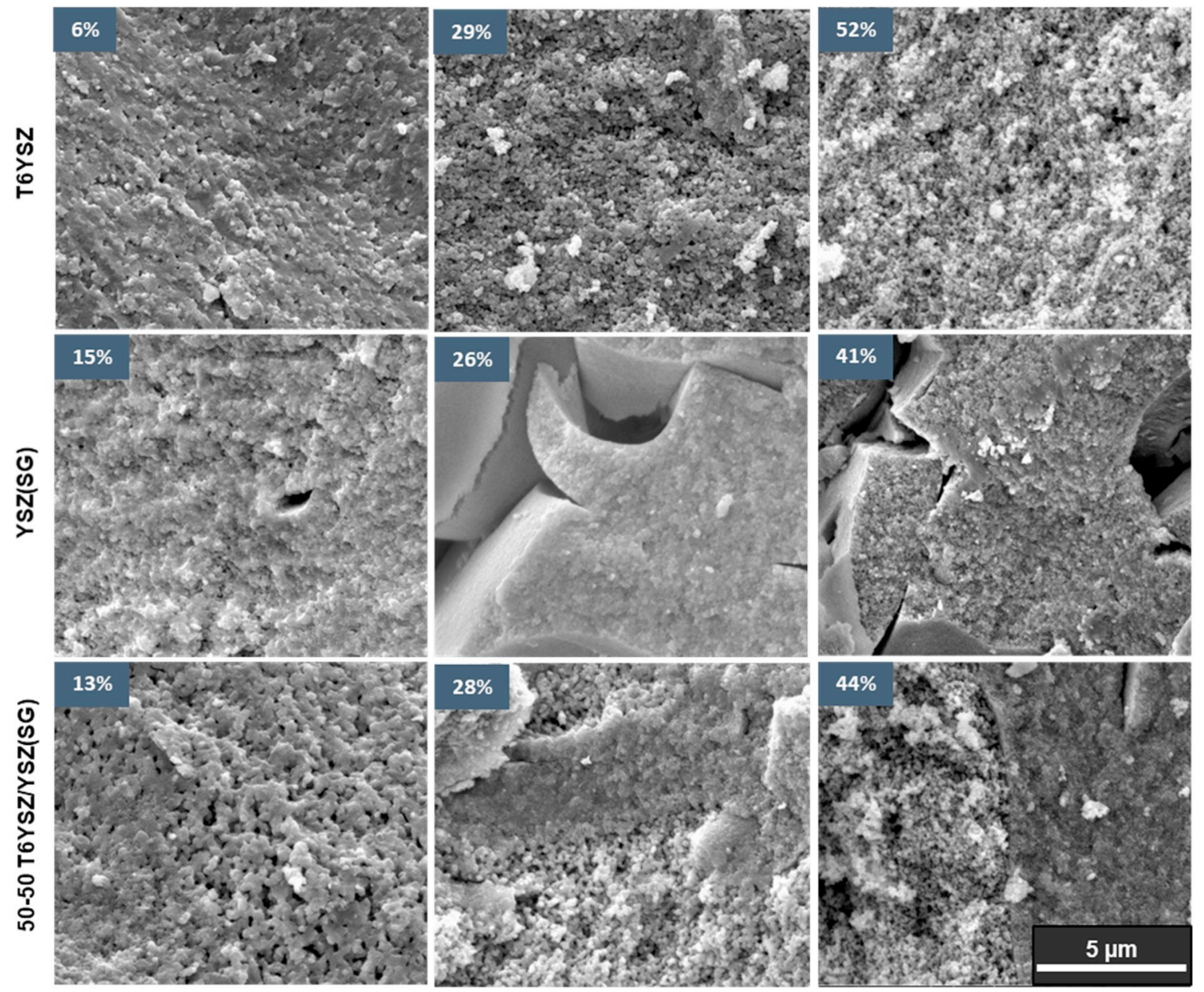

Fig. 6. SEM-FEG microstructure of the different powders for low, medium and high level of porosity at a high magnification.

Table 3

Evolution of the grain size (in $\mathrm{nm}$ ) of the sintered YSZ ceramics under $50 \mathrm{MPa}$ for $1 \mathrm{~min}$ as a function of the composition.

\begin{tabular}{lllll}
\hline Temperature & Composition & & & \\
& $100 \%$ & $100 \%$ & Mix 50/50 & \\
& T6YSZ & YSZ(SG) & T6YSZ & YSZ(SG) \\
$\mathbf{1 0 5 0}$ & $98 \pm 22$ & $68 \pm 17$ & $63 \pm 11$ & $73 \pm 18$ \\
$\mathbf{1 1 0 0}$ & $124 \pm 24$ & $77 \pm 23$ & $91 \pm 15$ & $77 \pm 14$ \\
$\mathbf{1 1 5 0}$ & $168 \pm 46$ & $127 \pm 37$ & $104 \pm 21$ & $84 \pm 11$ \\
\hline
\end{tabular}

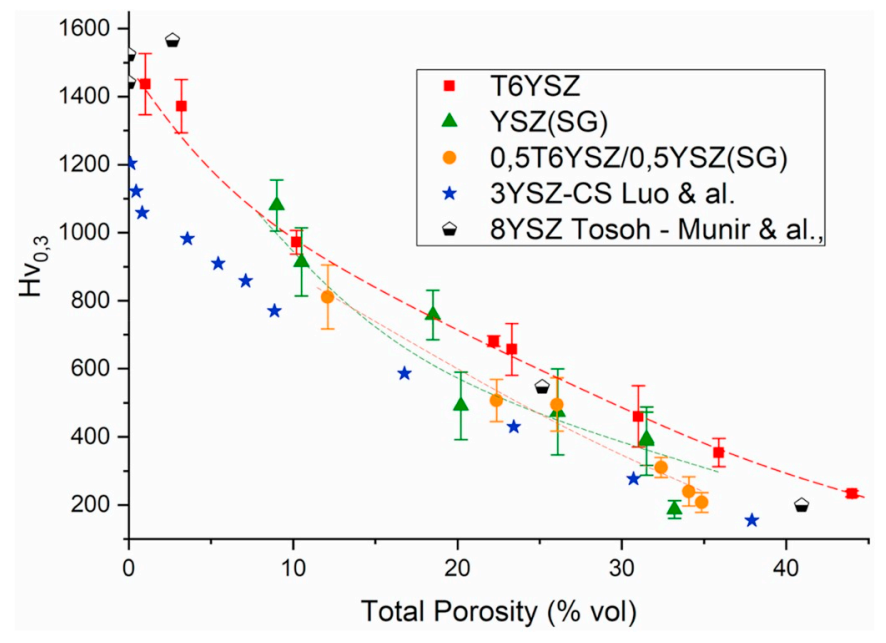

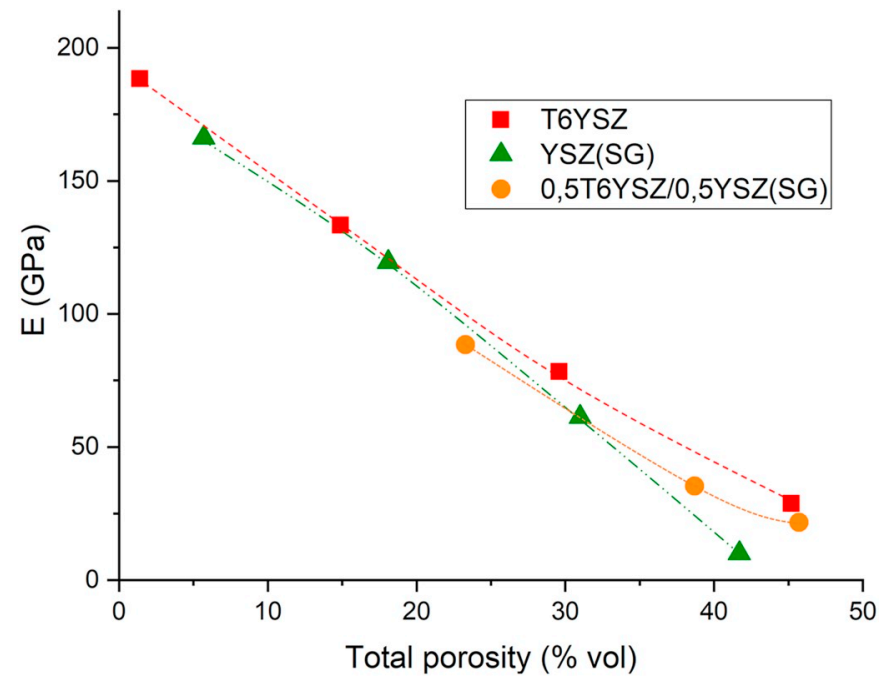

Fig. 8. Young Modulus measured by Acoustic Emission as a function of the porosity.

We did not check if the toughened transformation occurred after the flexural test, as we produce ceramics with high quantity of t' phase which is non-transformable under stress. This can explain why even for dense ceramics we did not reach high value of strength as $400 \mathrm{MPa}$ [21].

Fig. 7. Vickers Hardness as a function of the total porosity. 


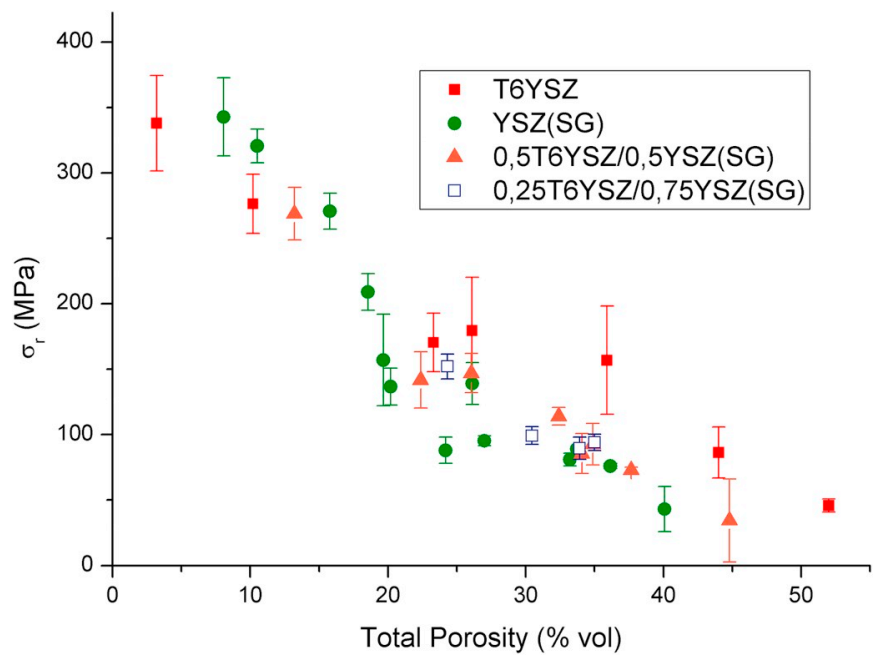

Fig. 9. Flexural strength as a function of the total porosity.

\section{Conclusions}

Spark plasma sintering is a versatile process which allowed the control of the microstructure and porosity rate by identifying the sintering parameters. Yttria stabilized zirconia from a commercial Tosoh powder and a micrometric synthetized by sol gel route powder were sintered by SPS and permitted to obtained nanostructured and mesoporous microstructure or oriented macroporous microstructure. Parameters to obtain porosity from 2 to $52 \%$ were well established for both powder and their mixture. It was found that the mixture seems to provoke some composite effects as the sintered density is lower than the powder only. It was demonstrated in previous works the possibility to apply this kind of microstructure on superalloy substrate and we checked the mechanical properties of the free-standing top coat thanks to the sintered pellets.

Hardness and strength of the materials obtained are highly dependent on the pore content, size and to the contact (neck area) between particles. They are also influenced by the shape of the porosity. For spherical pores (ie: Tosoh nanostructure) the strength evolved from 338 to $45,8 \mathrm{MPa}$ and hardness from 1375 to $186 \mathrm{Hv}$ for porosity in the range 3.2 to $52 \%$ while for oblate porosity (ie: YSZ(SG) the macroporous microstructure), which is the most detrimental, the strength evolved from 342.8 to $43.1 \mathrm{MPa}$ and hardness from 1130 to $303 \mathrm{Hv}$ for porosity in the range 8 to $40.1 \%$. It is also evidenced that the closed porosity, in particular for the YSZ(SG) system with low porosity content, also impacts the strength.

The evolution of the young modulus in acoustic emission shown no real difference between nano and microstructure, and the Young modulus decrease linearly from 195 to $16 \mathrm{GPa}$ with the increase of porosity in the range $0-50 \%$ vol. The decreased in a function of the porosity for the macrostructure one is higher. The composite exhibit a reinforcement by the nanopowder for porosity higher than $30 \% \mathrm{vol}$ because the values of the young modulus are closed to those of the T6YSZ. That permits to manage the mechanical properties with equivalent level of porosity and so to adapt it for different applications.

This work permitted to get all the primordial mechanical properties that are needed to understand the behavior of future application as TBC of YSZ ceramics made by SPS.

\section{Acknowledgments}

We would like to thank Safran Aircraft Engines (Site de Corbeil, Evry, France) and also the ANRT $\left(n^{\circ} 2016 / 0781\right)$ for the financial support.

\section{References}

[1] X.Q. Cao, R. Vassen, D. Stoever, Ceramic materials for thermal barrier coatings, J. Eur. Ceram. Soc. 24 (2004) 1-10, https://doi.org/10.1016/S0955-2219(03) 00129-8.

[2] D.R. Clarke, M. Oechsner, N.P. Padture, Thermal-barrier coatings for more efficient gas-turbine engines, MRS Bull. 37 (2012) 891-898, https://doi.org/10.1557/mrs. 2012.232.

[3] R. Darolia, Thermal barrier coatings technology: critical review, progress update, remaining challenges and prospects, Int. Mater. Rev. 58 (2013) 315-348, https:// doi.org/10.1179/1743280413Y.0000000019.

[4] D.D. Hass, A.J. Slifka, H.N.G. Wadley, Low thermal conductivity vapor deposited zirconia microstructures, Acta Mater. 49 (2001) 973-983, https://doi.org/10. 1016/S1359-6454(00)00403-1.

[5] F. Cernuschi, P. Bison, D.E. Mack, M. Merlini, S. Boldrini, S. Marchionna, S. Capelli, S. Concari, A. Famengo, A. Moscatelli, W. Stamm, Thermo-physical properties of as deposited and aged thermal barrier coatings (TBC) for gas turbines: state-of-the art and advanced TBCs, J. Eur. Ceram. Soc. 38 (2018) 3945-3961, https://doi.org/10. 1016/j.jeurceramsoc.2018.04.044.

[6] S. Paul, Stiffness of plasma sprayed thermal barrier coatings, Coatings 7 (2017).

[7] Y. Gu, X. Liu, G. Meng, D. Peng, Porous YSZ ceramics by water-based gelcasting, Ceram. Int. 25 (1999) 705-709, https://doi.org/10.1016/S0272-8842(99)00005-X.

[8] A.K. Gain, H.-Y. Song, B.-T. Lee, Microstructure and mechanical properties of porous yttria stabilized zirconia ceramic using poly methyl methacrylate powder, Scr. Mater. 54 (2006) 2081-2085, https://doi.org/10.1016/j.scriptamat.2006.03. 009.

[9] Z. Chen, X. Wang, F. Giuliani, A. Atkinson, Microstructural characteristics and elastic modulus of porous solids, Acta Mater. 89 (2015) 268-277, https://doi.org/ 10.1016/j.actamat.2015.02.014.

[10] A. Kishimoto, M. Obata, H. Asaoka, H. Hayashi, Fabrication of alumina-based ceramic foams utilizing superplasticity, J. Eur. Ceram. Soc. 27 (2007) 41-45, https://doi.org/10.1016/j.jeurceramsoc.2006.03.002.

[11] Z.A. Munir, U. Anselmi-Tamburini, M. Ohyanagi, The effect of electric field and pressure on the synthesis and consolidation of materials: a review of the spark plasma sintering method, J. Mater. Sci. 41 (2006) 763-777, https://doi.org/10. 1007/s10853-006-6555-2.

[12] R. Chaim, M. Levin, A. Shlayer, C. Estournès, Sintering and densification of nanocrystalline ceramic oxide powders: a review, Adv. Appl. Ceram. Struct. Funct. Bioceram. J. - Adv. Psychiatr. Treat. 107 (2008) 159-169.

[13] C. Estournès, D. Oquab, S. Selezneff, M. Boidot, D. Monceau, D. Grossin, C. Drouet, U.C. Chung, F. Roulland, C. Elissalde, M. Maglione, R. Chaim, P. Miele, J. GurtSantanach, G. Chevallier, A. Weibel, A. Peigney, Ch Laurent, Shaping of nanostructured materials or coatings through spark plasma sintering, Mater. Sci. Forum 706-709 (2012) 24-30 https://doi.org/10.4028/www.scientific.net/MSF.706709.24.

[14] R. Chaim, R. Marder, C. Estournès, Z. Shen, Densification and preservation of ceramic nanocrystalline character by spark plasma sintering, Adv. Appl. Ceram. 111 (2012) 280-285, https://doi.org/10.1179/1743676111Y.0000000074.

[15] O. Guillon, J. Gonzalez-Julian, B. Dargatz, T. Kessel, G. Schierning, J. Räthel, M. Herrmann, Field-assisted sintering technology/spark plasma sintering: mechanisms, materials, and technology developments, Adv. Eng. Mater. 16 (2014) 830-849, https://doi.org/10.1002/adem.201300409.

[16] R. Chaim, G. Chevallier, A. Weibel, C. Estournès, Grain growth during spark plasma and flash sintering of ceramic nanoparticles: a review, J. Mater. Sci. 53 (2018) 3087-3105, https://doi.org/10.1007/s10853-017-1761-7.

[17] D.V. Dudina, B.B. Bokhonov, E.A. Olevsky, Fabrication of porous materials by spark plasma sintering: a review, Mater. Basel Switz. 12 (2019), https://doi.org/10.3390/ ma12030541.

[18] U. Anselmi-Tamburini, J.E. Garay, Z.A. Munir, A. Tacca, F. Maglia, G. Spinolo, Spark plasma sintering and characterization of bulk nanostructured fully stabilized zirconia: Part I. Densification studies, J. Mater. Res. 19 (2004) 3255-3262, https:// doi.org/10.1557/JMR.2004.0423.

[19] U. Anselmi-Tamburini, J.E. Garay, Z.A. Munir, A. Tacca, F. Maglia, G. Chiodelli, G. Spinolo, Spark plasma sintering and characterization of bulk nanostructured fully stabilized zirconia: Part II. Characterization studies, J. Mater. Res. 19 (2004) 3263-3269, https://doi.org/10.1557/JMR.2004.0424.

[20] G. Bernard-Granger, C. Guizard, Spark plasma sintering of a commercially available granulated zirconia powder: I. Sintering path and hypotheses about the mechanism (s) controlling densification, Acta Mater. 55 (2007) 3493-3504, https://doi.org/10 1016/j.actamat.2007.01.048.

[21] T. Takeuchi, I. Kondoh, N. Tamari, N. Balakrishnan, K. Nomura, H. Kageyama, Y. Takeda, Improvement of mechanical strength of $8 \mathrm{~mol} \%$ yttria-stabilized zirconia ceramics by spark-plasma sintering, J. Electrochem. Soc. 149 (2002) A455-A461, https://doi.org/10.1149/1.1456915.

[22] R. K, H.U. S, S. R, C. Dibyendu, J. R, Comparative Evaluation of Spark Plasma (SPS), Microwave (MWS), two Stage Sintering (TSS) and Conventional Sintering (CRH) on the Densification and Micro Structural Evolution of Fully Stabilized Zirconia Ceramics, (2010), https://doi.org/10.2298/SOS1003259R.

[23] D. Monceau, D. Oquab, C. Estournes, M. Boidot, S. Selezneff, Y. Thebault, Y. Cadoret, Pt-modified Ni aluminides, MCrAlY-base multilayer coatings and TBC systems fabricated by Spark Plasma Sintering for the protection of Ni-base superalloys, Surf. Coat. Technol. 204 (2009) 771-778, https://doi.org/10.1016/j. surfcoat.2009.09.054.

[24] D. Monceau, D. Oquab, C. Estournès, M. Boidot, S. Selezneff, N. Ratel-Ramond, Thermal barrier systems and multi-layered coatings fabricated by spark plasma 
sintering for the protection of Ni-base superalloys, Mater. Sci. Forum 654-656 (2010) 1826-1831 https://doi.org/10.4028/www.scientific.net/MSF.654-656. 1826.

[25] S. Selezneff, M. Boidot, J. Hugot, D. Oquab, C. Estournès, D. Monceau, Thermal cycling behavior of EBPVD TBC systems deposited on doped Pt-rich $\gamma-\gamma^{\prime}$ bond coatings made by Spark Plasma Sintering (SPS), Surf. Coat. Technol. 206 (2011) 1558-1565, https://doi.org/10.1016/j.surfcoat.2011.06.011.

[26] F. Nozahic, D. Monceau, C. Estournès, Thermal cycling and reactivity of a MoSi2/ ZrO2 composite designed for self-healing thermal barrier coatings, Mater. Des. 94 (2016) 444-448, https://doi.org/10.1016/j.matdes.2016.01.054.

[27] J. Chevalier, L. Gremillard, A.V. Virkar, R.C. David, The tetragonal-monoclinic transformation in zirconia: lessons learned and future trends, Am. Sociol. 92 (2009) 1901-1920, https://doi.org/10.1111/j.1551-2916.2009.03278.x.

[28] R.M. Spriggs, Expression for effect of porosity on elastic modulus of polycrystalline refractory materials, particularly aluminum oxide, J. Am. Ceram. Soc. 44 (1961) 628-629, https://doi.org/10.1111/j.1151-2916.1961.tb11671.x.

[29] D. Hardy, D.J. Green, Mechanical properties of a partially sintered alumina, J. Eur. Ceram. Soc. 15 (1995) 769-775, https://doi.org/10.1016/0955-2219(95)00045-V.

[30] J.W. Adams, R. Ruh, K.S. Mazdiyasni, Young's modulus, flexural strength, and fracture of yttria-stabilized zirconia versus temperature, J. Am. Ceram. Soc. 80 (1997) 903-908, https://doi.org/10.1111/j.1151-2916.1997.tb02920.x.

[31] J. Luo, R. Stevens, Porosity-dependence of elastic moduli and hardness of 3Y-TZP ceramics, Ceram. Int. 25 (1999) 281-286, https://doi.org/10.1016/S0272 8842(98)00037-6.

[32] C. Viazzi, A. Deboni, J. Zoppas Ferreira, J.-P. Bonino, F. Ansart, Synthesis of Yttria Stabilized Zirconia by sol-gel route: influence of experimental parameters and large scale production, Solid State Sci. 8 (2006) 1023-1028, https://doi.org/10.1016/j. solidstatesciences.2006.02.053.

[33] J. Fenech, C. Viazzi, J.-P. Bonino, F. Ansart, A. Barnabé, Morphology and structure of YSZ powders: comparison between xerogel and aerogel, Ceram. Int. 35 (2009) 3427-3433, https://doi.org/10.1016/j.ceramint.2009.06.014.

[34] DongTao Jiang, Dustin M. Hulbert, Umberto Anselmi-Tamburini, Terry Ng, Donald Land, Amiya K. Mukherjee, Optically transparent polycrystalline Al2O3 produced by spark plasma sintering, J. Am. Ceram. Soc. 91 (2007) 151-154, https://doi.org/10.1111/j.1551-2916.2007.02086.x.

[35] S. Grasso, H. Yoshida, H. Porwal, Y. Sakka, M. Reece, Highly transparent a-alumina obtained by low cost high pressure SPS, Ceram. Int. 39 (2012) 3243-3248, https:// doi.org/10.1016/j.ceramint.2012.10.012.

[36] ISO/TC33 comité technique, ISO 5017:2013 - Produits réfractaires façonnés denses - Détermination de la masse volumique apparente, de la porosité ouverte et de la porosité totale, ISO, 2013.

[37] R.C. Garvie, P.S. Nicholson, Phase Analysis in zirconia systems, J. Am. Ceram. Soc. 55 (1972) 303-305, https://doi.org/10.1111/j.1151-2916.1972.tb11290.x.

[38] H. Toraya, M. Yoshimura, S. Somiya, Calibration curve for quantitative analysis of the monoclinic-tetragonal ZrO2 system by X-ray diffraction, J. Am. Ceram. Soc. 67 (1984) C-119-C-121, https://doi.org/10.1111/j.1151-2916.1984.tb19715.x.

[39] Z. Yan, C.L. Martin, O. Guillon, D. Bouvard, Effect of size and homogeneity of rigid inclusions on the sintering of composites, Scr. Mater. 69 (2013) 327-330, https:// doi.org/10.1016/j.scriptamat.2013.05.013.

[40] Y. Hirata, H. Fujita, T. Shimonosono, Compressive mechanical properties of partially sintered porous alumina of bimodal particle size system, Ceram. Int. 43 (2017) 1895-1903, https://doi.org/10.1016/j.ceramint.2016.10.149.

[41] R. Chaim, On densification mechanisms of ceramic particles during spark plasma sintering, Scr. Mater. 115 (2016) 84-86, https://doi.org/10.1016/j.scriptamat. 2016.01.010.

[42] S. Ghosh, Thermal barrier ceramic coatings - a review, Adv. Ceram. Process. (2015), https://doi.org/10.5772/61346.

[43] M. Mutter, G. Mauer, R. Mücke, O. Guillon, R. Vaßen, Correlation of splat morphologies with porosity and residual stress in plasma-sprayed YSZ coatings, Surf. Coat. Technol. 318 (2017) 157-169, https://doi.org/10.1016/j.surfcoat.2016.
12.061.

[44] C. LI, A. OHMORI, R. MCPHERSON, The relationship between microstructure and Young's modulus of thermally sprayed ceramic coatings, J. Mater. Sci. 32 (1997) 997-1004, https://doi.org/10.1023/A:1018574221589.

[45] G. Di Girolamo, F. Marra, C. Blasi, E. Serra, T. Valente, Microstructure, mechanical properties and thermal shock resistance of plasma sprayed nanostructured zirconia coatings, Ceram. Int. 37 (2011) 2711-2717, https://doi.org/10.1016/j.ceramint. 2011.04.024.

[46] X. Liu, C.L. Martin, G. Delette, D. Bouvard, Elasticity and strength of partially sintered ceramics, J. Mech. Phys. Solids 58 (2010) 829-842, https://doi.org/10. 1016/j.jmps.2010.04.007.

[47] A. Bravo-Leon, Y. Morikawa, M. Kawahara, M.J. Mayo, Fracture toughness of nanocrystalline tetragonal zirconia with low yttria content, Acta Mater. 50 (2002) 4555-4562, https://doi.org/10.1016/S1359-6454(02)00283-5.

[48] M. Trunec, Effects of Grain Size on Mechanical Propeties of 3Y-TZP Ceramics, (2008), p. 8

[49] W. Pabst, E. Gregorová, Young's modulus of isotropic porous materials with spheroidal pores, J. Eur. Ceram. Soc. 34 (2014) 3195-3207, https://doi.org/10. 1016/j.jeurceramsoc.2014.04.009.

[50] A.R. Boccaccini, Z. Fan, A new approach for the Young's modulus-porosity correlation of ceramic materials, Ceram. Int. 23 (1997) 239-245, https://doi.org/10. 1016/S0272-8842(96)00033-8.

[51] P. Planques, V. Vidal, P. Lours, V. Proton, F. Crabos, J. Huez, B. Viguier, Mechanical and thermo-physical properties of plasma-sprayed thermal barrier coatings: a literature survey, Oxid. Metals 88 (2017) 133-143, https://doi.org/10.1007/s11085016-9693-1.

[52] M. Mutter, G. Mauer, R. Mücke, O. Guillon, R. Vaßen, Systematic investigation on the influence of spray parameters on the mechanical properties of atmospheric plasma-sprayed YSZ coatings, J. Therm. Spray Technol. 27 (2018) 566-580, https://doi.org/10.1007/s11666-018-0697-z.

[53] B. Lv, R. Mücke, X. Fan, T.J. Wang, O. Guillon, R. Vaßen, Sintering resistance of advanced plasma-sprayed thermal barrier coatings with strain-tolerant microstructures, J. Eur. Ceram. Soc. 38 (2018) 5092-5100, https://doi.org/10.1016/j. jeurceramsoc.2018.07.013.

[54] F. Nozahic, Elaboration par Spark Plasma Sintering et caractérisation de composites et multi-couches zircone yttrié/MoSi2(B) pour application barrière thermique autocicatrisante, thesis, Toulouse, INPT, 2016, http://www.theses.fr/2016INPT0124 accessed October 26, 2018.

[55] D. Monceau, D. Oquab, C. Estournès, M. Boidot, S. Selezneff, N. Ratel-Ramond, Thermal barrier systems and multi-layered coatings fabricated by spark plasma sintering for the protection of Ni-base superalloys, Mater. Sci. Forum 654-656 (2010) 1826-1831 https://doi.org/10.4028/www.scientific.net/MSF.654-656. 1826.

[56] Y. Hirata, T. Shimonosono, T. Sameshima, S. Sameshima, Compressive mechanical properties of porous alumina powder compacts, Ceram. Int. 40 (2014) 2315-2322, https://doi.org/10.1016/j.ceramint.2013.07.153.

[57] L. Liang, Mechanical properties analysis and microstructure of ceramic materials of mullite ceramic material, Int. J. Electr. Eng. Educ. (2018), https://doi.org/10.1177/ 00207209188037090020720918803709.

[58] A.P. Roberts, E.J. Garboczi, Elastic properties of model porous ceramics, J. Am. Ceram. Soc. 83 (2000) 3041-3048, https://doi.org/10.1111/j.1151-2916.2000. tb01680.x.

[59] T. Shimonosono, T. Ueno, Y. Hirata, Mechanical and thermal properties of porous yttria-stabilized zirconia, J. Asian Ceram. Soc. 7 (2019) 20-30, https://doi.org/10 1080/21870764.2018.1547248.

[60] D.N. Boccaccini, H.L. Frandsen, S. Soprani, M. Cannio, T. Klemensø, V. Gil, P.V. Hendriksen, Influence of porosity on mechanical properties of tetragonal stabilized zirconia, J. Eur. Ceram. Soc. 38 (2018) 1720-1735, https://doi.org/10. 1016/j.jeurceramsoc.2017.09.029. 